\title{
A FORMAÇÃO DE UM SISTEMA AGRÁRIO HÍBRIDO: ESTUDO DE CASO SOBRE AS CONTINUIDADES E RUPTURAS NA AGRICULTURA FAMILIAR DE LAJEADO-RS ${ }^{1}$
}

\author{
Juliana Cristina FRANZ² \\ Giancarla SALAMONI
}

\section{Resumo}

O presente artigo analisa a configuração do sistema agrário colonial (SAC) e do sistema agrário moderno (SAM) no município de Lajeado/RS, no intuito de compreender a organização espacial atual da agricultura familiar local. A conformação do SAC combinou técnicas e práticas utilizadas nos sistemas agrários pré-existentes com os saberes e costumes trazidos da Alemanha. Na realidade pesquisada, as permanências relacionadas ao SAC ocorrem, principalmente, na dimensão sociocultural, através da reprodução de saberes e tradições, como língua, gastronomia, produção para autoconsumo e técnicas de manejo herdadas dos antepassados. Além disso, a centralidade da família e da propriedade da terra, ligada ao processo de herança, é marcadamente um elemento de continuidade na organização da agricultura familiar. Em relação aos elementos do SAM, que caracterizam as rupturas, o destaque cabe às dimensões técnicas e de produção, como a absorção de maquinário, inovações nas técnicas de plantio, no preparo do solo, na colheita e no uso de insumos bioquímicos. Consequentemente, o sistema agrário presente na agricultura familiar de Lajeado pode ser entendido a partir da combinação de elementos do SAC e do SAM, tendo como resultado continuidades e rupturas expressas no denominado sistema agrário híbrido $(\mathrm{SAH})$.

Palavras-chave: Imigração e Colonização Alemã. Sistemas Agrários. Cultura. Modernização.

\footnotetext{
${ }^{1}$ Este trabalho é parte da dissertação de mestrado de FRANZ, J. C. A Formação de um Sistema Agrário Híbrido: Estudo de caso sobre as continuidades e rupturas na agricultura familiar de Lajeado/RS. 2016.167 f. Dissertação (Mestrado em Geografia) Programa de Pós-Graduação em Geografia, Instituto de Ciências Humanas. Universidade Federal de Pelotas, 2016.

2 Doutoranda do Programa de Pós-Graduação em Geografia na Universidade Federal de Santa Maria. UFSM, Prédio 17, Sala 1132, Avenida Roraima, no 1000 - Santa Maria/RS. CEP: 97105900. E-mail: julianafranz@gmail.com

3 Professora Doutora na Universidade Federal de Pelotas (UFPel). ICH-UFPel, Rua Coronel Alberto Rosa, 154, Centro - Pelotas/RS. CEP. 96010-770. E-mail: gi.salamoni@yahoo.com.br
} 


\section{Abstract}

\section{The formation of a hybrid agrarian system: Case study on the continuities and ruptures in the family agriculture of Lajeado-RS}

This article analyzes the configuration of the colonial agrarian system (CAS) and the modern agrarian system (MAS) in the municipality of Lajeado/RS, in order to understand the current spatial organization of local family agriculture. The conformation of the CAS combined techniques and practices used in pre-existing agrarian systems, with the knowledge and customs brought from Germany. In reality researched, the stays related to CAS occur mainly in the social and cultural dimension, through the reproduction of knowledge and traditions such as language, gastronomy, production for self consumption and management techniques inherited from the ancestors. In addition, the centrality of the family and land ownership, linked to the process of inheritance, is markedly an element of continuity in the organization of family agriculture. Regarding the elements of MAS, which characterize the ruptures, the emphasis is on the technical and production dimensions, such as the absorption of machinery, innovations in planting techniques, soil preparation, harvesting and the use of biochemical inputs. Consequently, the agrarian system present in the family farm of Lajeado can be understood from the combination of CAS and MAS elements, resulting in continuities and ruptures expressed in the so-called hybrid agrarian system (HAS).

Agriculture.

Key words: Immigration and German Settlement. Agrarian Systems; Family

\section{INTRODUÇÃO}

A importância da agricultura familiar, na atualidade, reside na sua capacidade de adaptação e de reprodução social e territorial diante dos processos de transformação em curso na sociedade contemporânea. A terra, o trabalho e a família permanecem como dimensões indissociáveis, mesmo diante da modernização da agricultura e das inter-relações com o urbano. Por outro lado, as técnicas, as formas de socialização e até mesmo as características da população que compõe as propriedades familiares vêm mudando.

No intuito de compreender a organização e reprodução da agricultura familiar na atualidade no município de Lajeado/RS, a partir das continuidades e rupturas nos sistemas agrários locais, realizou-se um estudo de caso ancorado no viés qualitativo.

Primeiramente, foi realizada uma pesquisa bibliográfica sobre a formação do sistema agrário colonial (SAC), a partir da chegada dos imigrantes colonos alemães ao Brasil, mais especificamente ao Rio Grande do Sul, e sobre o decorrente processo de distribuição espacial associado a fatores políticos, sociais e econômicos. Assim, a conformação do SAC combinou técnicas e práticas utilizadas nos sistemas agrários pré-existentes, com os saberes e costumes trazidos da Alemanha.

A temática da modernização da agricultura foi analisada a partir dos elementos introduzidos pelas mudanças na base técnica. No intuito de responder quais são os elementos que persistem mesmo com o avanço da modernização da agricultura e de que forma o sistema agrário se organiza na atualidade no município de Lajeado/RS, buscou-se compreender os elementos socioculturais, de produção e técnicos presentes nas propriedades estudadas.

Foram realizadas entrevistas baseadas em roteiro semiestruturado em dez propriedades rurais. Posteriormente, realizou-se a tabulação dos dados e das infor- 
mações apreendidas em campo, confrontando-os com a base teórica adotada na pesquisa.

Ressalta-se que, para a ciência geográfica, este trabalho justifica-se ao estudar a organização espacial de uma determinada área. E, especificamente para a área de investigação da geografia agrária, procura-se promover um debate acerca dos entraves e das possibilidades de permanência da categoria social da agricultura familiar, considerando as especificidades do local.

O município de Lajeado/RS, recorte territorial da pesquisa (Figura 1), está situado na Mesorregião Centro-Oriental do Rio Grande do Sul, isto é, na porção centroleste do estado. Faz parte da microrregião do Vale do Taquari e configura parte da área denominada de "Colônia Velha". A terminologia Colônia Velha refere-se à região que foi primeiramente colonizada pelos imigrantes europeus, mais especificamente pelos alemães, no Rio Grande do Sul. Essa região representa a chamada zona pionei$\mathrm{ra}^{4}$ na constituição da agricultura familiar por colonos imigrantes alemães no Rio Grande do Sul, a qual imprimiu características específicas no espaço, como a configuração de pequenas propriedades policultoras com o uso de mão de obra familiar (ROCHE, 1969; SCHNEIDER, 1996).
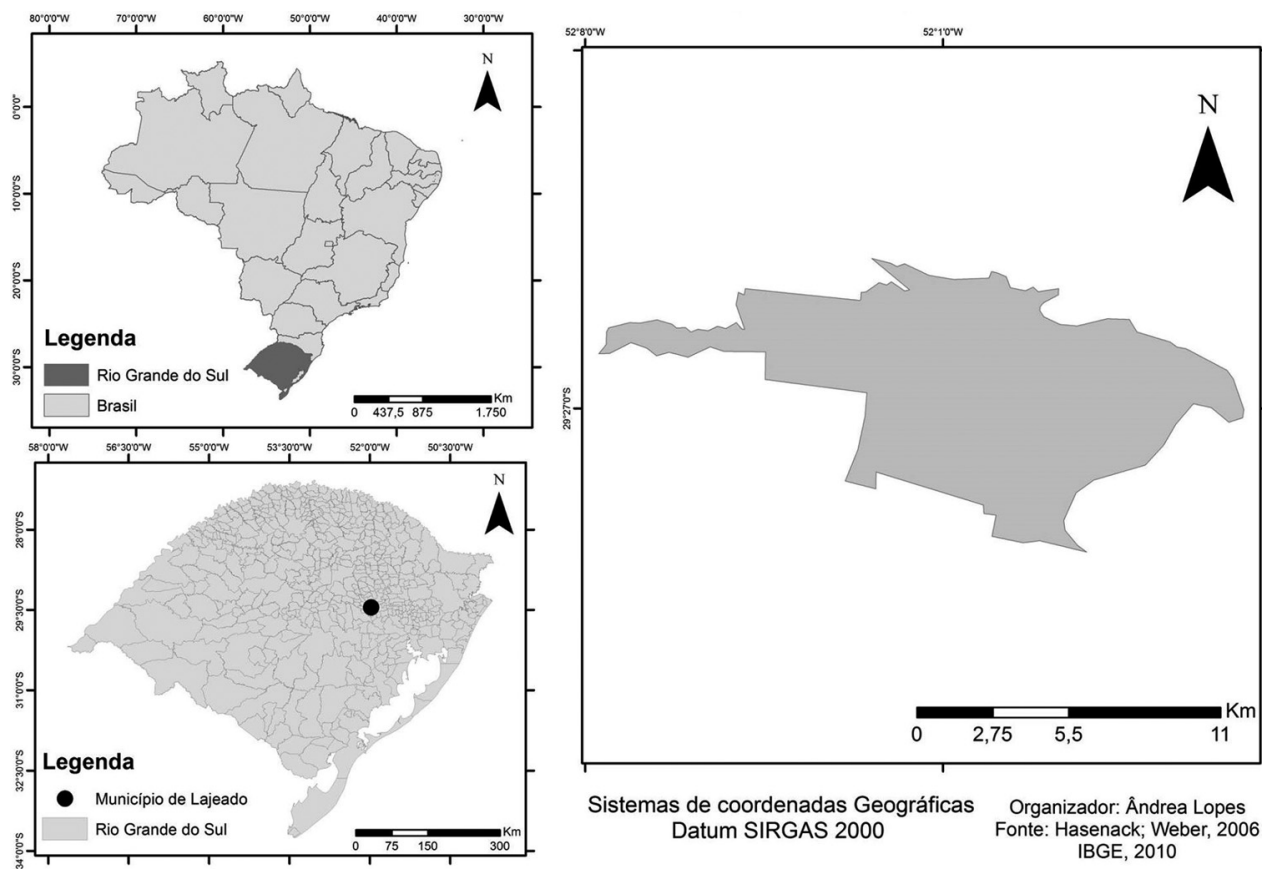

Sistemas de coordenadas Geográficas Organizador: Ândrea Lopes Datum SIRGAS 2000 Fonte: Hasenack; Weber, 2006 IBGE, 2010

\section{Figura 1 - Mapa de localização do estado do Rio Grande do Sul e do município de Lajeado/RS}

Fonte: Hasenack; Weber (2006); IBGE (2010)

Organizado por Ândrea Lopes (2016).

\footnotetext{
4 Segundo Waibel (1979), a zona pioneira é definida como sendo não apenas a expansão do povoamento espacialmente, mas também a intensificação e a criação de novos e mais elevados padrões de vida.
} 


\title{
CONSTITUIÇÃO DO SISTEMA AGRÁRIO COLONIAL
}

O processo de colonização alemã no Rio Grande do Sul teve, entre os principais fatores, o interesse do governo imperial e provincial no povoamento das áreas meridionais, garantindo assim a posse do território ao sul do Brasil, que era constantemente ameaçado pelos espanhóis. Os imigrantes alemães desembarcaram vindos da Europa, em diversos períodos, havendo a chegada dos primeiros imigrantes ocorrido em 1824 no Vale do Rio dos Sinos, quando ainda não se tinha uma legislação específica para a imigração (ROCHE, 1969).

Seyferth (1992) sintetiza a definição de colono que tem sua origem na administração colonial: "para o Estado, eram colonos todos aqueles que recebiam um lote de terras em áreas destinadas à colonização" (p. 80). Para esta autora (1992, p. 80), ainda o "colono é a categoria designativa do camponês [...] e sua marca registrada é a posse de uma colônia [...] a pequena propriedade familiar". Assim, no sul do Brasil, reconhecem-se e são conhecidos como colonos os agricultores descendentes de imigrantes europeus não portugueses que vivem e trabalham na terra em unidade de produção familiar.

O SAC, por sua vez, é conformado pela forma de produzir e pela forma de sociabilidade, e segundo Schneider (1996, p. 299):

\begin{abstract}
A forma de produzir refere-se à organização do trabalho num processo produtivo que seja capaz de assegurar a subsistência da família, é a maneira pela qual os indivíduos que trabalham organizam os meios de produção para garantir a sua reprodução. A forma de sociabilidade refere-se ao modo pelo qual estruturam-se as relações sociais que a família do colono-camponês estabelece com os elementos exteriores (SCHNEIDER, 1996, p. 299).
\end{abstract}

A sociabilidade pode ser estabelecida por meio de laços de parentesco, pelas relações entre vizinhos, pela religião, ou pelas atividades de lazer, podendo ocorrer em diferentes graus dependendo das relações estabelecidas pela família com o seu exterior. A ajuda mútua é uma característica fundamental na sociabilidade do colono imigrante.

A vida social dos colonos girava em torno de atividades relacionadas à igreja, sendo os encontros coletivos muito valorizados e semanais (geralmente aos domingos) (FALEIRO, 1996). Essa importância permanece até a atualidade, entretanto, a frequência desses encontros diminuiu, limitando-se a geralmente um encontro mensal, que permanece sendo aos domingos.

As igrejas também desempenharam um papel fundamental, pelo fato de a religião ser, depois do idioma, o elemento mais importante da vida social em comunidade.

Além da frequência na igreja, a população entrevistada também mantém uma relação bastante próxima com as festas das comunidades religiosas, católica e evangélica (luterana), que acontecem anualmente. Essas festas se mantêm ao longo dos anos e se reproduzem na atualidade. Além de jantares, bailes são as festas identificadas como as que continuam a ser reproduzidas nas comunidades com o passar do tempo. Os agricultores afirmam que as festas de hoje não são mais como antigamente, principalmente pela ensurdecedora música que não permite que conversem sobre o seu cotidiano, impedindo a plena sociabilidade entre as famílias. Os entrevistados rela- 
tam, também, que muitas festas desapareceram, ou se tornaram mais esporádicas, como é o caso do baile das flores, os típicos bailes de $K e r b^{5}$.

Quanto à sociabilidade dos integrantes dos grupos familiares entrevistados, observouse a participação de algumas mulheres nos jogos de bolão de mesa nas comunidades dos bairros. É importante ressaltar que esta atividade recreativa faz parte dos "Clubes de Mães", nos quais são participantes, em encontros mensais, geralmente aos sábados. Esta é considerada uma atividade de integração do grupo feminino, favorecendo o exercício do lazer e da coesão social entre as mulheres.

Becker (1987), ao analisar historicamente o jogo de bolão nas colônias alemãs, destaca que em todos os núcleos de colonização alemã existia a possibilidade de praticar tanto o bilhar quanto o bolão, mas foi apenas a partir de 1920 que o bolão tornou-se um jogo de lazer popular na zona de colonização alemã. O autor ainda aponta que os primeiros grupos de bolão iniciaram na região do Rio Pardo, do Jacuí e Taquari, mas nem sempre o jogo era praticado espontaneamente, ou seja, na maioria das vezes surgiu dentro das sociedades tradicionais ou de canto, de atiradores ou de ginástica.

O povoamento rural disperso, que ocorreu desde a chegada dos colonos no Rio Grande do Sul, caracterizou a forma de ocupação do espaço rural, em que os colonos iam estabelecendo suas moradias ao longo das picadas. Além dessa forma de ocupação do espaço, a etnia, a língua e a dificuldade de comunicações, principalmente pela falta de estradas, induziram a formação de uma sociedade com um alto grau de endogamia até 1950. "O caráter quase autárquico do modo de vida teuto-colonial era reforçado pelas intensas relações de parentesco e de religiosidade" (SCHNEIDER, 1996, p. 306).

Faleiro (1996) também expõe que a língua alemã, mantida pela prática familiar cotidiana, permitiu a continuidade dos laços com a nacionalidade alemã, em que ser "alemão" no Brasil significa falar alemão no cotidiano. Assim, a língua mantém a identidade étnica e religiosa.

Ao questionar acerca da comunicação através de algum dialeto alemão entre amigos e familiares, as respostas dos agricultores foram unânimes: em todas as propriedades continua-se falando o dialeto alemão, e este conhecimento é repassado aos mais jovens, isto é, aos filhos ou netos. Em alguns casos, os jovens compreendem a língua, mas não a falam. Entre as famílias, a reprodução do dialeto, além de ser uma questão cultural que vem se reproduzindo, também é vista muitas vezes como um saber a mais que pode vir a facilitar o acesso a um emprego na cidade, principalmente no comércio, tendo em vista que é uma língua bastante reproduzida no município e arredores, e, em alguns casos, pessoas idosas têm dificuldade de se comunicar em português.

Outras atividades desenvolvidas no interior das propriedades também fazem parte deste sistema, como é o caso do artesanato rural. O uso do espaço no lote colonial também é outro elemento considerado essencial pelos colonos desde a sua chegada até a constituição da propriedade da terra. Oitenta por cento das propriedades entrevistadas ainda preservam alguma atividade de artesanato herdada de seus antepassados. As principais atividades são o crochê e o tricô, que são produzidos manualmente pelas mulheres, principalmente no turno da noite, ou à tarde quando o sol está muito quente para trabalhar nas atividades agrícolas. Em três propriedades entrevistadas, a atividade apontada foi a confecção de balaios - com a utilização de três tipos distintos de material, vime, palha de milho e cipó com bambu -, atividade esta desenvolvida pelos homens.

\footnotetext{
5 O termo Kerb tornou-se uma forma abreviada do Kirchweihfest, festa de inauguração da igreja (LENZI, 1989, p. 16). Para os católicos, também é a festa em homenagem ao padroeiro da igreja.
} 
Nas propriedades rurais visitadas, a herança dos antepassados também está presente na preservação dos costumes ${ }^{6}$ relacionados à culinária, o "saber-fazer" no preparo dos alimentos. "A comida, ao mesmo tempo em que está alicerçada em razões práticas - é necessária para atender ao estômago -, também constrói seu universo simbólico - é necessária para atender à mente" (WOORTMANN, 2007, p. 178). A comida tradicional alemã sofreu adaptações, devido ao impacto do turismo e da migração para áreas urbanas de descendentes dos colonos.

Na consciência étnica dos teuto-brasileiros, a comida aparece como um dos marcadores culturais da identidade. Seyferth (2015) ressalta que os hábitos alimentares surgiram da conciliação de uma imaginada tradição nacional com a produção que era obtida nas roças da colônia. E o mais marcante é a policultura, que até hoje é valorizada mesmo nas propriedades pluriativas.

Entre os produtos em destaque estão o pão e a cuca7, que são feitos artesanalmente para o consumo próprio das famílias. As conservas e compotas também são típicas entre os agricultores, que, com sua elaboração, buscam armazenar e conservar frutas e legumes da época para serem consumidos posteriormente, geralmente durante o ano todo, seguindo a lógica de aprovisionamento dos colonos pioneiros. Também a produção de melado ${ }^{8}$ e de schmier $^{9}$ ainda é comum nas propriedades, e geralmente o excedente desta produção é comercializado na própria propriedade.

A manutenção do "saber-fazer" nas propriedades também é observada em relação às ervas medicinais, que são conservadas para consumo doméstico na sua forma in natura ou ainda processadas em formato de pomadas, óleos ou repelentes naturais. A confecção de sabão caseiro, à base de sebo bovino, também é uma prática cultural ainda reproduzida nas propriedades, mesmo que em menor frequência e intensidade do que em época anterior. A principal causa apontada é a falta de tempo, em geral por haver pouca mão de obra disponível para a realização do trabalho na propriedade, além desta também foram mencionadas a facilidade de acesso aos mercados e a mudança de hábitos decorrente da introdução da energia elétrica.

Em todas as propriedades entrevistadas, o "saber-fazer" em relação à culinária e à conservação dos alimentos é repassado aos mais jovens ou ainda, nas palavras dos agricultores, eles "tentam" repassar esses costumes aos filhos e netos. Como Seyferth (2015, p. 137) expõe, habitus é conhecimento adquirido, supõe socialização, aprendizado, orienta a ação, cabendo destaque à mãe, que aparece como "uma espécie de guardiã simbólica da identidade". Neste caso, a culinária é um exemplo da cultura (material e imaterial) envolvendo a identidade étnica.

Por mais que a comida característica dos colonos alemães tenha sofrido alterações ao longo do tempo, ela não desapareceu, foi ressignificada, retida na memória gastronômica do grupo, foi revalorizada como comida ritual das festas, em que a identidade e os laços de parentesco são reforçados e as raízes familiares são atualizadas (WOORTMANN, 2007).

Em relação à prática da ajuda mútua entre os agricultores familiares, seja por laços de parentesco ou vizinhança, nas atividades agrícolas, o relato dos agricultores é de que esta diminuiu com o passar do tempo em função da modernização da agri-

\footnotetext{
6 Costumes: "sugere práticas e comportamentos aceitos pelo grupo, associados a uma tradição, aprendidos no curso da socialização" (SEYFERTH, 2015, p. 138).

7 Cuca é uma massa feita com fermento biológico, trigo, açúcar, manteiga e ovos, aberta num tabuleiro e coberta com pedaços de frutas e Streusel (mistura esfarelada de açúcar, trigo e manteiga) (SEYFERTH, 2015).

8 Melado é um produto decorrente da cana-de-açúcar e sua pasta é a base do schmier.

9 Espécie de doce consistente à base de melado e composto de frutas e mandioca (ROCHE, 1969).
} 
cultura e, por vezes, pelo fato de algumas famílias não desempenharem mais as atividades agrícolas, pois se dedicam exclusivamente ao trabalho não agrícola, pela proximidade com o urbano.

Os trabalhos manuais relacionados à capina e ao plantio, principalmente do milho, e ao uso da tração animal na carroça e no arado foram as práticas tradicionais mais mencionadas nas respostas dos entrevistados. Além da continuidade no trabaIho que já vinha sendo desempenhado pelos seus antecessores, a manutenção da criação animal diversificada, da reprodução ao abate, para o consumo doméstico é apontada como uma herança cultural.

Alguns dos aspectos de produção que conformam o SAC e que ainda são reproduzidos na atualidade são: a pequena propriedade com base na mão de obra familiar, o sistema de produção fundamentado na policultura - na qual está inclusa a pecuária de pequeno porte, especialmente a pecuária leiteira, e o cultivo de alimentos para o autoconsumo - foi bastante lembrado, principalmente pela manutenção da horta e do pomar, assim como a comercialização do excedente da produção. Inclui-se também a própria herança da terra, que é considerada pelos grupos familiares entrevistados como uma continuidade do legado dos seus antepassados, uma vez que os agricultores familiares atuais reproduzem o ofício aprendido com seus pais e avós.

A continuidade da comunicação no dialeto alemão, a frequência na igreja, os saberes culinários e as atividades de artesanato são exemplos de aspectos socioculturais que os agricultores familiares herdaram dos seus antepassados e buscam repassar para a geração mais jovem, mesmo com ressignificações e adaptações.

\section{FORMAÇÃO DE UM SISTEMA AGRÁRIO MODERNO}

A modernização da agricultura pode ser definida como sendo o processo através do qual ocorrem mudanças na base técnica de produção. Principalmente através do uso intensivo de máquinas e insumos químicos e inovações, como no método e técnicas de preparo do solo, de tratos culturais e em processos de colheita mais sofisticados (GAZOLLA, 2004).

Assim, a agricultura, ao sofrer os efeitos do processo de modernização, teve como reflexos imediatos desde a diminuição de sua autonomia em relação ao mercado até o retraimento do círculo da família absorvida pelo processo produtivo. Mesmo com a modernização e com a integração socioeconômica alterando as dinâmicas da agricultura familiar, não houve "a implantação de uma forma social de produção única e homogeneizada" (WANDERLEY, 2009, p. 185). Quanto à alteração no modo de vida tradicional do camponês, principalmente através da aspiração ao modo de vida moderno, à modernização e à integração aos complexos agroindustriais (CAIs), esta não atingiu todos os agricultores, e Wanderley (2009) considera que a produção familiar sobrevive pelo fato de o produtor estar apto a produzir para o mercado, e este, por sua vez, apresenta uma demanda pelos produtos daquele.

A integração aos CAIs desencadeia certa especialização produtiva por parte dos agricultores "[...] a agricultura de diversificada tende à especializada" (GRANDO; MERTZ, 2010, p. 102). A integração é um processo seletivo e, consequentemente, excludente, pois requer que a produção agrícola absorva as inovações tecnológicas voltadas à agricultura e, de certa forma, desarticula o sistema tradicional dos agricultores que consistia em associar a policultura à pequena produção de animais. Dessa forma, a produção passa do sistema simples de mercadoria para a integração e sub- 
missão ao modo de produção capitalista dominante. E os agricultores familiares mostraram grande capacidade de se adaptar às diferentes situações.

Sucintamente, Grando e Mertz (2010) elencam os principais fatores que ocasionaram mudanças na agricultura familiar, em específico no Rio Grande do Sul, e destacam a modernização da agricultura e o avanço da industrialização nas zonas rurais. Essas variáveis influenciam na estrutura social das comunidades rurais (na diferenciação de integração/exclusão ao sistema moderno de produção); no modo de produção dos agricultores (com a imposição tecnológica da agroindústria ocorreu a simplificação dos sistemas de produção para uns, e a geração de busca por novas estratégias para outros); no modo de vida (pela expansão da sociedade do consumo); e na paisagem rural (pelo aumento das redes de comunicação - estradas -, pelo turismo rural, ou ainda pelos usos não agrícolas).

Grando e Mertz (2010) também apontam a especulação fundiária como outra face perversa do modelo de modernização implantado, em que as terras mais aptas à mecanização valorizaram e induziram os pequenos proprietários a se desfazer das suas propriedades. Por outro lado, Marafon (2015) considera que o desenvolvimento tecnológico permitiu melhoria nos meios de comunicação, como nas estradas, na telefonia e nos meios de transporte, e isso resultou no crescimento de atividades não agrícolas no meio rural, tornando o espaço rural mais complexo.

Em relação à absorção da modernização no campo estudado, questionou-se sobre a plantação de cultivares transgênicos nas propriedades rurais, e averiguou-se que $80 \%$ das propriedades plantam sementes transgênicas. Isso é percebido pelos agricultores como um processo inevitável diante da introdução da modernização na agricultura. Silva (2011, p. 145) debate acerca da indisponibilidade de sementes de variedades não transgênicas (convencionais) no mercado no sul do Brasil, o que impossibilita aos agricultores o direito ao acesso a essas sementes. Nas palavras do autor: "Isto é um caso de erosão genética".

Também se questionou sobre o uso de inseminação artificial no rebanho animal, procedimento utilizado em $90 \%$ das propriedades, principalmente no gado bovino para a reprodução e, em algumas propriedades, também para a manutenção de uma raça bovina específica.

As respostas dos agricultores familiares em relação à modernização ativeramse, principalmente, à questão da mecanização, exemplificando com o uso de trator, rotativa, debulhador elétrico de milho, prensadora de cana, ordenhadeira, resfriador de leite, plantadeira, colheitadeira e pulverizador. Contudo, em alguns casos, as respostas também consideraram a mudança no método de manejo do solo, através da introdução do plantio direto e da rotação de culturas, pela conservação do milho através da silagem para o trato animal. A plasticultura, a irrigação e as estufas foram outros elementos da modernização absorvidos pelos agricultores.

Sucintamente, em relação aos aspectos técnicos e produtivos das propriedades entrevistadas, a preponderância recaiu sobre a absorção da modernização, principalmente no quesito das inovações mecânicas, nas diferentes fases da cultura (plantio, preparo do solo, adubação e colheita), bem como no uso de insumos bioquímicos. Entretanto, ressalta-se que não foram obtidas respostas homogêneas, ou seja, as propriedades absorveram a modernização em diferentes graus de intensidade. 


\title{
CONCLUSÃO: A CONFORMAÇÃO DE UM SISTEMA AGRÁRIO HÍBRIDO
}

\begin{abstract}
Ao longo do tempo, muitas das dinâmicas internas relacionadas à organização das famílias rurais foram alteradas; entretanto, práticas sociais, técnicas e produtivas vêm se mantendo como estratégias de reprodução desses agricultores. No que tange aos aspectos socioculturais, percebem-se novos hábitos combinados com práticas e saberes herdados dos antepassados, tanto na agricultura quanto no artesanato, na alimentação, ou ainda nas atividades de socialização entre os grupos familiares. Aspectos do SAC continuam sendo reproduzidos na atualidade, entretanto, estão associados aos elementos que caracterizam o SAM. Percebe-se assim, a presença dos dois sistemas agrários no mesmo espaço.

De posse das informações coletadas em campo e em consonância com a revisão teórica, entende-se que a reprodução das propriedades familiares do município de Lajeado ocorre em um duplo de continuidades e rupturas que são absorvidas no cotidiano, no manejo e nas técnicas de modernização absorvidas após a Revolução Verde. Entretanto, este processo não foi uniforme, isto é, em algumas propriedades permanece o trabalho manual ou com tração animal como caráter principal, ou ainda como complementares ao processo modernizador.

Assim, é possível compreender que características que configuram o SAC permanecem sendo reproduzidas no cotidiano das famílias rurais estudadas, e estas são complementadas com fatores que caracterizam o SAM. A partir da simbiose de características de ambos os sistemas agrários no cotidiano das famílias, principalmente nos sistemas sociocultural, técnico e de produção, aos quais a análise de campo se deteve. Desta forma, leva-se a proposição de que estes agricultores conformam, a partir de continuidades e rupturas, o denominado sistema agrário híbrido (SAH) na realidade local estudada.

Em síntese, compreende-se que o sistema agrário presente na agricultura familiar estudada é constituído de continuidades, principalmente no sistema sociocultural, e também é permeado por rupturas, com destaque ao sistema técnico e produtivo, conforme pôde ser averiguado com os dados de campo. Entretanto, é importante ressaltar que no sistema sociocultural modernidades também foram absorvidas no rearranjo das práticas culturais, bem como no sistema técnico e de produção também há permanências do sistema colonial, como a policultura, o uso de tração animal e trabalho manual em algumas propriedades. Dessa forma, identifica-se a conformação de um SAH.
\end{abstract}

\section{REFERÊNCIAS}

BECKER, K. O esporte de Bolão no Rio Grande do Sul. In: SIMPÓSIO DE HISTÓRIA DA IMIGRAÇÃO E COLONIZAÇÃO ALEMÃ NO RIO GRANDE DO SUL, 4., 1980, São Leopoldo. Anais... São Leopoldo: UFRGS, 1987. p. 249-264.

FALEIRO, S. R. Lajeado Perfil Histórico Étnico-Social (do período indígena à colonização). Lajeado: Prefeitura Municipal de Lajeado, 1996.

FRANZ, J. C. A formação de um sistema agrário híbrido: estudo de caso sobre as continuidades e rupturas na agricultura familiar de Lajeado/RS. $167 \mathrm{f}$. Dissertação (Mestrado em Geografia) Programa de Pós-Graduação em Geografia, Universidade Federal de Pelotas, 2016. 
GAZOLLA, M. Agricultura familiar, segurança alimentar e políticas públicas: uma análise a partir da produção para autoconsumo no território do Alto Uruguai/RS. 2004. 287f. Dissertação (Mestrado em Desenvolvimento Rural) - Universidade Federal do Rio Grande do Sul, Porto Alegre, 2004.

GRANDO, M. Z.; MERTZ, M. M. De colonos a agricultores familiares: uma trajetória de resistência. In: CONCEIÇÃO, Octávio Augusto Camargo

et al. (Org.). O movimento da produção. Porto Alegre: FEE, 2010. p. 93-128.

GRAZIANO DA SILVA, J. Tecnologia \& Agricultura Familiar. Porto Alegre: UFRGS, 1999.

instituto brasileiro de geografia e estatística (IBge). Primeiros Dados do Censo, 2010. Disponível em: <http://www.ibge.gov.br/censo2010/ primeiros_dados_divulgados/

index.php> Acesso em: 13 abr. 2015.

LENZI, Z. M. O Kerb em Santa Catarina. Florianópolis: Ed. UFSC, 1989.

MARAFON, G. J. O trabalho de campo como um instrumento de trabalho para o investigador em geografia agrária. In: DAVID, C.; WIZNIEWSKY, C. R. F. (Org.). Agricultura \& Transformações socioespaciais. Porto Alegre: Evangraf/Jadeditora, 2015. p. 26-46.

ROCHE, J. A Colonização Alemã e o Rio Grande do Sul. Porto Alegre: Ed. Globo, 1969.

SCHNEIDER, S. Os colonos da indústria calçadista: expansão industrial e as transformações da agricultura familiar no Rio Grande do Sul. Ensaios FEE, Porto Alegre, v.17, n.1, p.298-323, 1996.

SEYFERTH, G. A Colonização alemã em Santa Catarina: hábitos alimentares e etnicidade. In: MENASCHE, R. (Org.) Saberes e Sabores da Colônia. Porto Alegre: UFRGS, 2015. p.133-160.

SEYFERTH, G. As contradições da liberdade: análise de representações sobre a identidade camponesa. Revista Brasileira de Ciências Sociais, São Paulo, v. 7, n. 18, p. 78-95, fev. 1992.

SILVA, M. T. Violação de Direitos e Resistência aos Transgênicos no Brasil: uma proposta camponesa. In: ZANONI, M.; FERMENT, G. (Org.). Transgênicos para Quem? Brasília: MDA, 2011. p.446-461.

WANDERLEY, M. N. Urbanização e Ruralidade: relações entre a pequena cidade e o mundo rural. Estudo preliminar sobre os pequenos municípios em Pernambuco. In: WANDERLEY, M. N. O mundo rural como um espaço de vida. Porto Alegre: UFRGS, 2009. p. 311-328.

WOORTMANN, E. F. Padrões Tradicionais e Modernização: comida e trabalho entre camponeses teuto-brasileiros. In: MENASCHE, Renata (Org.). Agricultura Familiar à Mesa: Saberes e práticas da alimentação no Vale do Taquari. Porto Alegre: UFRGS, 2007. p.177-96. 